contingency plan was made: to devise a triage screening tool and implement triage clinics at CIRC to help reduce its dental waiting list. Triage appointments were booked and conducted. 20-patients were seen: 12-patients required urgent care; eight patients, detained less than a year, required routine care. All urgent problems were booked appointments. The 20-patients were removed from the waiting list. This led to a reduction of patients, therefore, reduced waiting times.

Quality improvement and its use in enhancing practice performance; decision-making theories within triage systems and screening tools; the value of evidence-based dentistry, and the importance of evidence-based management and strategic decision-making were significant learning points. Working with healthcare, administrative and officer teams encouraged collaborative leadership. In medical and secure establishments, dental teams may not always be present. Thus, some sort of triage system and screening tool should exist, so that patients can receive dental advice or emergency first-aid care from suitably trained staff. This will be of particular importance to medical staff, in perhaps, preventing inappropriate antibiotic prescribing.

\section{LEADING ON THE IMPLEMENTATION OF A COVID JUNIOR DOCTOR ROTA}

${ }^{1} \mathrm{G}$ McHale, ${ }^{2} \mathrm{~N}$ O'Reilly. 'Greenwich GPVTS, London, UK; ${ }^{2}$ Barts Health, London, UK

\subsection{6/leader-2020-FMLM.74}

Aims We developed and implemented a new Junior Doctor rota at a small DGH in London in the weeks approaching the peak of the COVID19 pandemic.

In early March 2020, it became clear it would be necessary to increase junior doctor staffing in order to provide roundthe-clock care for acutely unwell patients, while ensuring cover for staff sickness. Failure would result in significant strain on staff wellbeing and patient safety.

Methods We assessed the challenge by discussing with colleagues, meeting the site medical director and joining calls with strategic leaders.

Central hospital planning provided details of expected clinical need and acuity. Junior doctors were engaged in daily handover meetings and via instant messaging.

We developed a rota covering all medical wards, increasing on-call and night staffing and ensuring adequate rest. We split the hospital into zones and organised colleagues into colourcoded teams. This provided team spirit and support in a difficult environment. Evident immediately were improvements in both perceptions of patient safety and morale.

Results We carried out a survey of colleagues. Of the approximately 60 colleagues involved, 37 responded to 21 questions. $(\mathrm{A}=$ Agree, $\mathrm{SA}=$ Strongly Agree, $\mathrm{N}=$ Neutral $)$

Perceptions of safe ward staffing before and after rota introduction: $32 \%$ vs $86 \%$ (A/SA)

Perceptions of safe on-call staffing before and after rota introduction: $24 \%$ vs $92 \%$ (A/SA)

Adequate notice on COVID rota change: $73 \%(\mathrm{~A} / \mathrm{SA} / \mathrm{N})$

Adequate consultation on COVID rota change: $92 \%$ (A/ $\mathrm{SA} / \mathrm{N})$
Team-based rota pattern beneficial $86 \%$ (A/SA)

Conclusions This work identified the need for adequate consultation when changing working practices. Successful leadership requires the ability to communicate in difficult circumstances and to implement necessary change despite time pressures. The benefits of team-based work were clearly demonstrated and should be carried forward to maintain morale.

\section{Leveraging artificial intelligence to improve $\mathrm{CV}$ risk awareness in diabetes patients}

\section{DEMONSTRATING LEADERSHIP IN HEALTH CARE: UTILISING ARTIFICIAL INTELLIGENCE TO IMPROVE NCD OUTCOMES}

Anurita Majumdar*, Kaushal Shetty, Kannan Subramaniam. Research, Development and Medical, Pfizer Upjohn, Singapore, Business Technology, Research, Development and Medical, Pfizer Upjohn, Mumbai, India, Research, Development and Medical, Pfizer Upjohn, Sydney, Australia

\subsection{6/leader-2020-FMLM.75}

Context Noncommunicable diseases (NCDs) are responsible for more than $71 \%$ of all deaths worldwide and more than $85 \%$ of these deaths are premature and in low- and middleincome countries. Diabetes is one of four key NCDs, the others being cardiovascular disease (CVD) chronic respiratory illness and cancer. Those with diabetes are at high risk for CVD and are two to four times more likely to die from CVD than those without. 1 in 10 people with diabetes were not aware about CVD and its risk factors; greater than 9 in 10 had one or more risk factors for CVD; and 1 in 4 thought their risk for CVD was low or none. These results of a study conducted by the International Diabetes Federation in 2017/2018 reported that in South East Asia more than half those studied reported that they were at no or low risk of CVD. Furthermore, almost 1 in 5 could not recall having discussed risk for CVD with their clinician. Thailand's National Health Examination Survey III showed that approximately half of the people with the coexistence of hypertension and diabetes were unaware of either one condition and $85 \%$ of them were unaware of having both conditions. Researchers conclude that efforts to increase detection, treatment, and control of those affected are critical. A multisectoral approach involving key stakeholders and leveraging technology with credible information can be used to address the challenge.

Intervention We leveraged artificial intelligence to address two key issues; identify persona of diabetes patients who are not aware of their risk for CVD and provide targeted information to raise awareness and improve adherence. The Medical Lead for NCDs, the Regional Medical Lead for ASEAN and the Regional Business Technology (BT) Lead led the design and execution of this strategic project in Thailand. Our teams included country medical and regional portfolio and BT leads. A defined project management plan with milestone reviews helped execute this project on time. 